\title{
Fatigue resistance of press hardened 22MnB5 steels
}

Sergi Parareda ${ }^{1}$, Daniel Casellas ${ }^{1,2}$, David Frómeta ${ }^{1}$, Marc Martínez ${ }^{1}$, Antoni Lara ${ }^{1}$, Anna Barrero' ${ }^{1}$ Jaume Pujante ${ }^{1}$

[1] Eurecat, Centre Tecnològic de Catalunya, Plaça de la Ciència 2, 08243 Manresa, Spain

[2] Division of Mechanics of Solid Materials, Luleå University of Technology, 971 87 Luleå, Sweden

\begin{abstract}
In press hardened steels, fatigue behaviour is very sensitive to surface defects or irregularities, either intrinsic or introduced during trimming operations. This work addresses the understanding and prediction of fatigue resistance of press hardened steels from a fracture mechanics approach. The size of fatigue originating defects were evaluated and used to estimate the fatigue limit for different surface conditions (coated and uncoated), different coatings (Al-Si and $\mathrm{Zn}$ ) and different edge condition (polished and mechanically trimmed). Good agreement was found between calculated and experimental values, which shows the potential of fracture mechanics to estimate the fatigue performance of press hardened steels.
\end{abstract}

\section{Introduction}


Press hardening of Boron steels, mainly the $22 \mathrm{MnB} 5$ grade, has been implemented during more than a decade in several structural components of the automotive sector, mostly in the body in white (BiW). The process combines sheet forming and heat treatment in one single die quenching step, to produce components with complex geometry and strength up to $1600 \mathrm{MPa}$ [1]. High crash performance parts achieving weight savings around $25 \%$ can be effectively manufactured at a competitive cost, using this robust and flexible process.

These well-established technology/product innovations in the automotive industry for BiW parts could be transferred to other applications (such as chassis parts) or transport markets (such as light-duty and heavy-duty vehicles). However, the requirements for these applications involve requirements fundamentally different from BiW parts, mainly high mechanical demands in terms of cyclic loads. In such parts, the fatigue resistance becomes the key design parameter, so any attempt to transfer press hardening technologies to chassis part manufacturing or truck sector must deal with fatigue performance.

Fatigue resistance of press hardening steels has received much less attention than crashworthiness, which has been deeply investigated and improved to successfully apply them in BiW. Scarce data is available in the open literature about the fatigue behaviour of $22 \mathrm{MnB} 5$ steels. The available works show that press hardened steels are very sensitive to pre-existing defects [2-6], namely cracks in the sheet coating or shear edge defects introduced by punching or trimming.

About the former, common practice in hot stamping of thin 22MnB5 sheet includes the use of Al-Si coating to prevent scaling and decarburization. This coating develops into an intermetallic layer during austenitization [1,7], which is extensively 
cracked after die quenching. Such cracks act as fatigue initiation points and decrease fatigue resistance, as showed by the works of Picas et al. [2]. and Pessard et al. [6].

On the latter, chassis parts usually require of trimming or punching operations, which introduce damage in terms of cracks or surface irregularities in the cut edges. The fatigue part performance is affected by such edge defects, which determines the steel applicability. Fatigue performance of press hardened 22MnB5 is more sensitive to pre-existent defects than other very high strength steels, as stated by Lara et al. [4]. They showed that the fatigue limit obtained in defect-free (polished) specimen is markedly reduced in specimens with surface defects or trimmed edges, much more than complex phase or dual phase steels. Such defect sensitivity has to be seriously considered when evaluating the use of press hardened steels for fatigue dimensioned parts.

Linear Elastic Fracture Mechanics (LEFM) concepts are widely used to describe the fatigue life of parts or specimens with defects. Crack growth can be described by the well-known Paris-Erdogan law for a wide range of engineering materials. As showed in previous works, the fatigue life of coated or trimmed 22MnB5 steels is controlled by the propagation of pre-existent defects. It means that LEFM could be a suitable tool to predict their fatigue resistance. Accordingly, this work focusses on evaluating the fatigue performance of press hardened 22MnB5 steels by using LEFM concepts and considering the nature of fatigue origins, i.e. coatings cracks, surface irregularities or defects at the trimmed edge.

\section{Materials and experimental procedure}


The investigated steel is $22 \mathrm{MnB} 5$, the most commonly used grade for press hardening. Different conditions were selected to evaluate the effect of sheet thickness, surface condition and damage in trimmed edges on fatigue.

Two different sheet thickness ranges were considered, thin sheet as used in automotive BiW (1.5-1.7 $\mathrm{mm}$ range), and thicker $3.0 \mathrm{~mm}$ sheet, closer to a potential light or heavy duty vehicle application. Three different surface conditions were investigated: Al-Si coating, Zn-based coating and uncoated surface. The effect of edge damage on fatigue behaviour was evaluated by trimming the calibrated zone of fatigue specimens in the press hardened state. Two cutting clearances, $6 \%$ and $10 \%$, were used. Figure 1 shows the trimming die and the trimmed specimen. For the polished edge condition, the specimens were obtained by Electrical Discharge Machining (EDM) and polished to specular finish. Edge grinding and polishing is necessary to erase the fusion zones and recast layers introduced by the EDM cutting process. Table 2 summarizes the tested specimen conditions.

Specimens were heat treated in the conditions showed in Table 1 and die quenched in a flat water-cooled tool. The resulting microstructure was fully martensitic for both sheet thicknesses (figure 2(c)).

After heat treatment, the Al-Si coated specimen show the typical coating characteristics: five-layer structure formed by alternating $\mathrm{Fe}_{2} \mathrm{Al}_{3}$ and $\mathrm{T}_{1} \mathrm{Al}-\mathrm{Fe}-\mathrm{Si}$ intermetallic and a Fe-based diffusion layer [7]. The Zn-based coating corresponds to a galvanized 90/90 coating (figure 1 (b)). Coating microstructure after heat treatment consists of grains of Zn-saturated $\alpha$ Fe surrounded by $\Gamma-Z n$ [8]. Samples showed no macroscopic affectation by liquid metal embrittlement; this can be expected due to the flat geometry of the specimen. Both Al-Si and Zn-based coatings are well adhered to the substrate and cracks run through the entire coating thickness and 
stop at the diffusion layer, without progressing into the substrate (Figure 2). Al-Si and $\mathrm{Zn}$ coatings have similar thickness, in the range of 25 to $30 \mu \mathrm{m}$.

Tensile tests under monotonic loading were performed in a universal testing machine. Fracture toughness $\left(K_{I c}\right)$ was also estimated from elastic-plastic fracture mechanics measurements from a previous work in thin press hardened specimens [9]. The reported value of essential work of fracture, equivalent to the $J_{I C}$ parameter, was converted into $K_{l c}$ using the following equation:

$$
K_{I C}=\sqrt{J_{I C} E}
$$

where $E$ is the Young's modulus.

Fatigue resistance was evaluated in terms of fatigue limit and fatigue crack propagation. Fatigue limit was evaluated in tensile tests, performed at room temperature on a resonance fatigue testing machine (frequency of $80 \mathrm{~Hz}$ ) using a load ratio $(R)$ of 0.1 . The fatigue limit, $\sigma_{F A T}$, was evaluated at 2 million cycles following the staircase method. A minimum of 15 specimens were tested for each group. Fatigue crack propagation was performed according to ASTM E-647 procedure. Crack propagation rate results, $d a / d N$, were fitted to the Paris-Erdogan law:

$$
\frac{d a}{d N}=A \Delta K^{m}
$$

where $a$ is the crack length, $N$ the number of cycles and $A$ and $m$ are the Paris coefficients, which were obtained from experimental data fitting. The crack propagation threshold, $\Delta K_{T H}$, was defined as the value of the stress intensity range $(\Delta K)$ giving a crack propagation velocity lower than $10^{-11} \mathrm{~m} / \mathrm{cycle} . \Delta K$ is defined according to LEFM:

$$
\Delta K=Y \Delta \sigma \sqrt{\pi a}
$$


where $Y$ is a dimensionless factor that accounts for the crack geometry and $\Delta \sigma$ is the applied stress amplitude. The crack configuration (a sharp through thickness crack) is similar to a single edge notch tension (SENT) specimen, where $Y=1.13$ as determined by Murakami [10].

\section{$3 \quad$ RESULTS}

Hardness and tensile properties are reported in Table 1. They lie within the expected range for $22 \mathrm{MnB} 5$ steels with a martensitic microstructure.

The fatigue limit is shown in Figure 3 and summarized together with crack propagation resistance in Table 3. As expected, the surface condition determines the fatigue behaviour. Trimmed specimens show the lowest fatigue limit, whereas uncoated specimens show the highest one. As expected, this is related to the dimensions of the pre-existent surface defects, which act as fatigue origins and shorten the fatigue life. Different surface irregularities or defects control the fatigue life in the tested specimens, i.e. cracks in the coating in coated specimens (Figure 4), surface irregularities in uncoated specimens (Figure 5) and edge defects in trimmed specimens (Figures 6 and 7).

Both the $\mathrm{Al}-\mathrm{Si}$ and the $\mathrm{Zn}$ coatings are extensively cracked after press hardening (Figure 2(a)) and such cracks reduced the fatigue life compared to uncoated steels, acting as fatigue initiation sites (Figures $4(b)-(d)$ ). It can be also discerned that coating cracks grow during fatigue tests and propagate into the 22MnB5 substrate (Figure 4(e)). In uncoated specimens fatigue starts from surface irregularities (Figure 5). In the trimmed edge four different zones can be discerned; rollover, smooth and fracture zone and the burr (figure 1(b)). Fatigue origins are associated to surface irregularities of the trimmed edge. Defect location depends on the trimming 
clearance. Fatigue starts at the transition between the smooth and the fracture zone for specimens trimmed at 6\% (Figure 6), whereas defects are located at the fracture zone for specimens trimmed at 10\% (Figure 7). Such effect of trimming clearance on fatigue origin is well reported for other high strength steels $[4,11]$.

The fatigue crack propagation resistance is shown in Figure 8 and Table 3. The propagation rate for thick and thin $22 \mathrm{MnB} 5$ steels is very similar, but they considerably differ in the propagation threshold. It is higher in thin specimens than in thick ones. Such difference is not related to microstructural features, both show martensitic microstructure. It is related to different stress state due to the specimen thickness. Figure 9 shows the different crack propagation features for thin and thick specimens. The thin specimens show a slant fracture (associated to plane stress state) meanwhile thick ones show pronounced shear lips in the fracture surface (associated to mixed-mode stress state) [12]. Thus, the measured $\Delta K_{T H}$ for 1.5-1.7 $\mathrm{mm}$ thickness specimens, in plane stress, is larger than the $\Delta K_{T H}$, measured for $3.0 \mathrm{~mm}$ thickness specimens, in mixed plane stress-strain.

\section{$4 \quad$ DISCUSSION}

Results show that pre-existent defects as coating cracks or surface irregularities at the trimmed edges are the fatigue initiation sites. Following LEFM concepts, the fatigue limit $\left(\sigma_{F A T}\right)$ can be estimated from the crack size leading to fatigue failure (a) and $\Delta K_{T H}$ using equation (3). It can be rewritten as

$$
\Delta K_{T H}=Y \Delta \sigma_{F A T} \sqrt{\pi a_{0}}
$$


The value of $a_{0}$ can be associated to the coating thickness for coated specimens, to the edge damage in trimmed specimens and to the surface irregularities in uncoated specimens. Aimed at quantifying $a_{0}$ for each condition, the trimmed and the uncoated surfaces were inspected by optical profilometry. A complete scan of the whole trimmed edge (more than 8.000 linear profiles) was done for 5 specimens. The edge profile of trimmed specimens shows pronounced surface intrusions. The dimensions and morphology of such surface irregularities depend on the trimming clearance and sheet thickness, being them larger for higher trimming clearances. Such surface intrusions act as fatigue origin (figures 6 and 7 ), so their size can be considered as $a_{0}$. It was quantified considering $a_{0}$ as the deepest valley from the surface profile. Figure 10 shows the surface roughness of a trimmed edge with the surface profile of the deepest defect. For uncoated specimens the dimensions and morphology of the initial defects are less evident. To be consistent with the measurements done in trimmed specimens, the surface parameter that represents the maximum valley height from the surface profile $\left(R_{v}\right)$ was chosen. All the measured values of surface defects are shown in table 3.

The estimated values for $\sigma_{F A T}$, using aovalues shown in table 3, are plotted in Figure 11. They match very well with the experimental values. Estimations are especially good for edge polished specimens, both coated and uncoated. It might be related to the fact that initial defects, coating cracks and surface irregularities, are well defined. For trimmed specimens the estimation is less accurate, probably because edge defects are not homogenous (it may differ from specimen to specimen) and other factors as residual stresses or local stress concentration should be also considered.

The good estimations show the relevance of selecting the appropriate initial defect size. In coated specimens it is clear, the coating thickness can be taken as ao. In 
trimmed or uncoated surface the selection of a surface parameter that resembles the fatigue initiation parameter is crucial. It is widely accepted that surface roughness affects fatigue life [13] but there is still unclear which surface parameter should be used to estimate the fatigue limit. The average roughness amplitude, $R_{a}$, is widely used to characterize a surface finish, but it has inherent limitations to describe the effect of surface roughness on the fatigue behaviour [14]. Present results show that the measure of the deepest valley from the surface profile (parameter $R_{v}$ ) give good estimations of fatigue limit. Accordingly, $R_{v}$ might be suggested as a good surface descriptor for fatigue estimations.

Another point to be discussed is the use of long crack (in the order of $\mathrm{mm}$ ) parameters $\left(\Delta K_{T H}\right)$ to predict the fatigue limit of specimen with small defects (in the order of $\mu \mathrm{m})$. Small crack behaviour is always a concern when applying LEFM to natural crack behaviour [15]. The question here is if the studied cracks (in the range of 15$70 \mu \mathrm{m})$ can be considered as small cracks. The microstructural feature controlling the propagation of fatigue cracks is the martensite block size $[16,17]$. These are typically lower than $1 \mu \mathrm{m}$, so it is clear that coating or trimming cracks are not microstructurally small. Cracks can be considered as mechanically small when the near crack tip plasticity is comparable to the crack size. The equation (5) can be used to estimate the radius of the cyclic plastic zone $\left(r_{c}\right)$ [18]:

$$
r_{c}=\frac{1}{\pi}\left(\frac{\Delta K_{I}}{2 \sigma_{Y}}\right)^{2}
$$

Where $\Delta K_{l}$ is equivalent to $\Delta K_{T H}$ at the fatigue limit stress. Using the values of $\Delta K_{T H}$ and $\sigma_{y}$ from table $3, r_{c}$ is around 1-2 $\mu \mathrm{m}$ for the tested steels. Again, cracks cannot be seen as mechanically small. Finally, differences between the $\Delta K_{T H}$ for small and long cracks can come from crack closure effects. In order to discern the presence of crack closure the fracture surface of Compact Tension (CT) specimens (used to 
obtain fatigue crack growth from long cracks) and fatigue specimens (small cracks) was inspected by scanning electron microscopy (SEM) and compared. Fracture surface for both specimens are mostly transgranular, without clear differences between them (Figure 12). The relatively flat feature of fatigue fracture surfaces and the transgranular crack propagation type allows suggesting that crack closure is not relevant for the investigated surface conditions in press hardened 22MnB5 steels.

The good estimation of fatigue limit, from $\Delta K_{T H}$ obtained with long cracks (Figure 11), means that LEFM is a useful approach to estimate and understand the fatigue performance of press hardened 22MnB5. This is mainly explained by the absence of small crack behaviour, which allows using fatigue crack propagation threshold obtained for long cracks to estimate the behaviour of small cracks and by the fact that fatigue is controlled by well-defined pre-existent defects.

\section{$4 \quad$ Conclusions}

This work shows that fatigue resistance of press hardened 22MnB5 may be estimated following LEFM concepts. It has been experimentally supported by fatigue results obtained from different surface conditions, as those for coated, uncoated and mechanically trimmed specimens. Experimental evaluation of fatigue limits and fatigue origin allowed to drawn the following conclusions:

-Fatigue of press hardened 22MnB5 steels is controlled by pre-existent surface defects, as cracks in the coating, surface irregularities or defects at the trimmed edges. 
-Good agreement has been found between estimated and experimental fatigue limit values when considering the size of the fatigue triggering defects and the material properties governing their propagation, i.e. the fatigue crack propagation threshold. Proper evaluation of defect size and location is essential to obtain good estimations.

-No small crack behaviour has been detected, which allows pointing out that the fatigue resistance properties evaluated for long cracks $\left(\Delta K_{T H}\right)$ can be readily used to estimate the fatigue limit for specimens with coating or processing defects.

\section{References}

[1] H. Karbasian, A.E. Tekkaya, A review on hot stamping. Journal of Materials Processing Technology, 210 (2019) 2103-2118.

[2] I. Picas, R. Muñoz, A. Lara, R. Hernández, D. Casellas, "Effect of the cutting process in the mechanical and fatigue properties of press hardened 22MnB5 steel", Proceedings of the $3^{\text {rd }}$ International Conference on Hot Sheet Metal Forming of High-Performance steel (ISBN 978-3-942267-17-5) pp. 85-92, (2011).

[3] I. Picas, A. Lara, D. Casellas, A. Ademaj, K. Steinhoff., "Fatigue performance of press hardened steels with tailored material properties: a compromise between high strength and damage tolerant microstructures", Proceedings of the $4^{\text {th }}$ International Conference on Hot Sheet Metal Forming of High-Performance steel (ISBN 978-3-942267-82-3), pp. 251-258 (2013). 
[4] A. Lara, I. Picas, D. Casellas. Effect of the cutting process on the fatigue behaviour of press hardened and high strength dual phase steels, Journal of Materials Processing Technology, 213 (2013) 1908-1919.

[5] C. Sunderkötter, A. Wollenberg ,C. Pfeffer, H. Sieurin, I. Annegren, "Press hardening of truck chassis components", $5^{\text {th }}$ Int. Conf. on Steel in Cars and Trucks (2017)

[6] E. Pessard, B. Abrivard, F. Morel, F. Abroug, P. Delhaye, The effect of quenching and defects size on the HCF behaviour of Boron steel, International Journal of Fatigue; 68 (2014) 80-89.

[7] R. Grigorieva, P. Drillet, J.M. Mataigne, A. Redjaïmia. Phase transformations in the Al-Si coating during the austenization step, Solid State Phenomena 174 (2011), 748-790

[8] Exploring of crack initiation mechanisms and process parameter interactions in press hardened boron steel components actively protected by $\mathrm{Zn}$-based coatings (ZINCOBOR) (RFCS project; 2012-2015)

[9] S. Golling, D. Frómeta, D. Casellas, P. Jonsén, Influence of microstructure on the fracture toughness of hot stamped boron steel, Material Science and Engineering A, 743 (2019) 529-539.

[10] Y. Murakami, 1987. Stress intensity factor handbook, Vol. 2. Pergamon Press, Oxford.

[11] E. Maronne, A. Galtier, J.I. Robert, T. Ishikawa, Cutting process influence on fatigue sheet properties, Transactions on Engineering Science 40 (2003) 1322. 
[12] D. Broeck, Elementary engineering fracture mechanics, Martin Nijhoof Publishers (1982) pp 107-111.

[13] H. Itoga, K. Tokaji, M. Nakajima, H.K. Ko, Effect of surface roughness on step-wise S-N characteristics in high strength steel, International Journal of Fatigue, 25 (2003) 379-385.

[14] A. Zabala, L. Blunt, W. Tato, A. Aginagalde, X. Gómez, I. Llavori, The use of areal surface topography characterization in relation to fatigue performance, MATEC Web of Conferences 16514013 (2018)

[15] M. D. Chapetti, Fatigue propagation threshold of short cracks under constant amplitude loading, International Journal of Fatigue 25 (2003) 1319-1326

[16] S. Morito, H. Yoshida, T. Maki, X. Huang, Effect of block size on the strength of lath martensite in low carbon steels, Material Science and Engineering $A$ 438-440 (2006) 237-240.

[17] S. Li, G. Zhu, Y. Kang, Effect of substructure on mechanical properties and fracture behaviour of lath martensite in $0.1 \mathrm{C}-1.1 \mathrm{~S}-1.7 \mathrm{Mn}$ steel, Journal of Alloys and Compounds 675 (2016) 104-115.

[18] S. Suresh, Fatigue of Materials, Cambridge University Press (1998) pp. 302306. 


\section{TABLES}

Table 1: Material surface conditions, austenitizing conditions, hardness (HV1) and mechanical properties, as yield stress $\left(\sigma_{\mathrm{y}}\right)$, ultimate tensile strength (UTS), total elongation (TE) and fracture toughness $\left(K_{l c}\right)$.

\begin{tabular}{|c|c|c|c|c|c|c|c|}
\hline $\begin{array}{l}\text { Thick- } \\
\text { ness } \\
(\mathrm{mm})\end{array}$ & Surface & $\begin{array}{c}\text { Austen- } \\
\text { itizing }\end{array}$ & HV1 & $\sigma_{y}(\mathbf{M P a})$ & $\begin{array}{l}\text { UTS } \\
\text { (MPa) }\end{array}$ & TE (\%) & $\begin{array}{c}K_{I c}(\mathrm{MPa} \\
\left.\mathrm{m}^{1 / 2}\right)\end{array}$ \\
\hline 1.7 & $\mathrm{Al}-\mathrm{Si}$ & $\begin{array}{c}900^{\circ} \mathrm{C} \\
390 \mathrm{~s}\end{array}$ & $494 \pm 3$ & $\begin{array}{c}1330 \pm \\
11\end{array}$ & $\begin{array}{c}1560 \pm \\
10\end{array}$ & $\begin{array}{c}6.6 \pm 0.2 \\
(\mathrm{~A} 80)\end{array}$ & \\
\hline 1.5 & Zn Gl90/90 & $\begin{array}{c}900^{\circ} \mathrm{C} \\
255 \mathrm{~s}\end{array}$ & $473 \pm 9$ & $\begin{array}{c}1052 \pm \\
23\end{array}$ & $1452 \pm 52$ & $\begin{array}{c}5.3 \pm 0.6 \\
(\mathrm{~A} 50)\end{array}$ & 183 \\
\hline 1.7 & Uncoated & $\begin{array}{c}900^{\circ} \mathrm{C} \\
390 \mathrm{~s}\end{array}$ & $444 \pm 9$ & $\begin{array}{c}1098 \pm \\
33\end{array}$ & $1603 \pm 10$ & $\begin{array}{c}7.0 \pm 0.4 \\
(\mathrm{~A} 80)\end{array}$ & \\
\hline 3.0 & Uncoated & $\begin{array}{c}930 \stackrel{\circ}{ }= \\
330 \mathrm{~s}\end{array}$ & $\begin{array}{l}483 \\
\pm 12\end{array}$ & $\begin{array}{c}1124 \pm \\
22\end{array}$ & $\begin{array}{c}1528 \pm \\
15\end{array}$ & $\begin{array}{c}7.4 \pm 0.6 \\
(\mathrm{~A} 50)\end{array}$ & - \\
\hline
\end{tabular}

Table 2: Conditions for tested specimens.

\begin{tabular}{|l|c|c|c|}
\hline Denomination & Thickness $(\mathbf{m m})$ & Surface & Edge \\
\hline $\begin{array}{l}\text { Al-Si coated, pol- } \\
\text { ished }\end{array}$ & 1.7 & Al-Si coating & Polished \\
\hline
\end{tabular}




\begin{tabular}{|l|c|c|c|}
\hline $\begin{array}{l}\text { Zn-coated, pol- } \\
\text { ished }\end{array}$ & 1.5 & Gl90/90 coating & Polished \\
\hline Uncoated, thin & 1.7 & No coating & Polished \\
\hline Uncoated, thick & 3.0 & No coating & Polished \\
\hline Trimmed 6\% & 1.7 & Al-Si coating & $6 \%$ clearance \\
\hline Trimmed 10\% & 1.7 & Al-Si coating & $10 \%$ clearance \\
\hline
\end{tabular}

Table 3: Fatigue limit ( $\left.\sigma_{F A T}\right)$ in terms of the maximum stress, fatigue crack propagation threshold $\left(\Delta K_{T H}\right)$ and Paris law parameters $(A, m)$.

\begin{tabular}{|c|c|c|c|c|}
\hline Specimen & $\begin{array}{c}\sigma_{\mathrm{FAT}} \\
(\mathrm{MPa})\end{array}$ & $\begin{array}{c}\Delta \mathrm{K}_{\mathrm{TH}} \\
\left(\mathrm{MPa} \mathrm{m}^{1 / 2}\right)\end{array}$ & $\begin{array}{c}\mathbf{A} \\
(\mathrm{m} /(\text { cyc } M P a))\end{array}$ & m \\
\hline Al-Si polished & $652 \pm 53$ & \multirow{5}{*}{5.8} & \multirow{5}{*}{$1.1910^{-11}$} & \multirow{5}{*}{2.66} \\
\hline Zn-coated polished & $660 \pm 56$ & & & \\
\hline Trimmed 6\% & $437 \pm 27$ & & & \\
\hline Trimmed $10 \%$ & $391 \pm 33$ & & & \\
\hline Uncoated thin & $761 \pm 38$ & & & \\
\hline Uncoated thick & $528 \pm 53$ & 3.8 & $1.8810^{-11}$ & 2.59 \\
\hline
\end{tabular}

Table 4: Surface defects associated with fatigue origins. They are considered as initial fatigue crack ( $\left.a_{0}\right)$ and used for fatigue limit computation using equation (4). 


\begin{tabular}{|c|c|c|}
\hline Specimen & Defect & $\mathbf{a}_{0}(\boldsymbol{\mu m})$ \\
\hline Al-Si polished & Coating thickness & $25 \pm 5$ \\
\hline Zn-coated polished & Coating thickness & $25 \pm 5$ \\
\hline Trimmed 6\% & Surface intrusion at trimmed edge & $46 \pm 2$ \\
\hline Trimmed 10\% & Surface intrusion at trimmed edge & $68 \pm 10$ \\
\hline Uncoated thin & Deepest valley from surface profile, $R_{v}$ & $18 \pm 4$ \\
\hline Uncoated thick & Surface intrusion at trimmed edge & $17 \pm 4$ \\
\hline
\end{tabular}




\section{FIGURES}

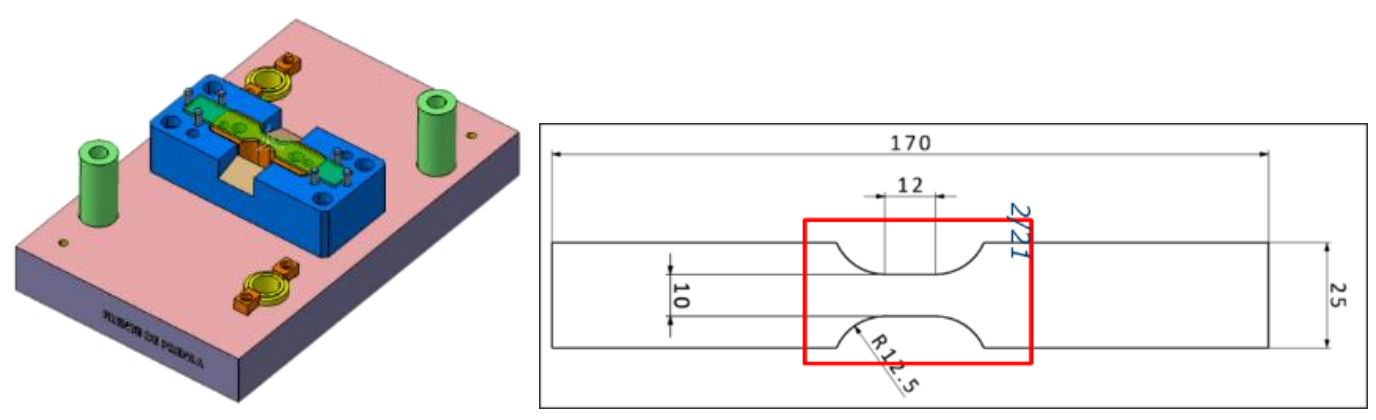

(a)
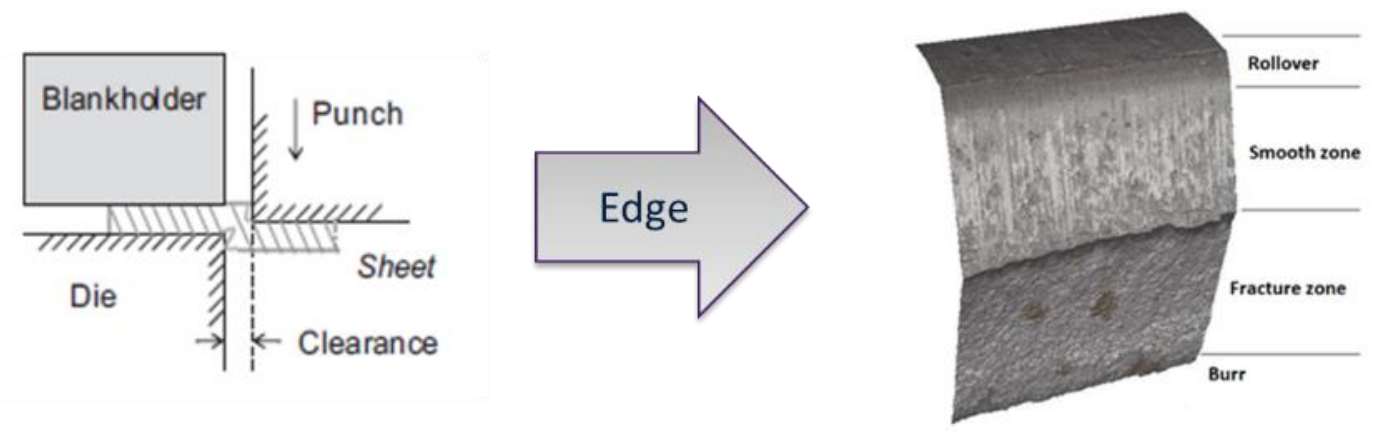

(b)

Figure 1: (a) Trimming tool and fatigue specimen with the trimmed area (rectangle).

(b) Drawing of punching operation and different zones at the trimmed edge. 


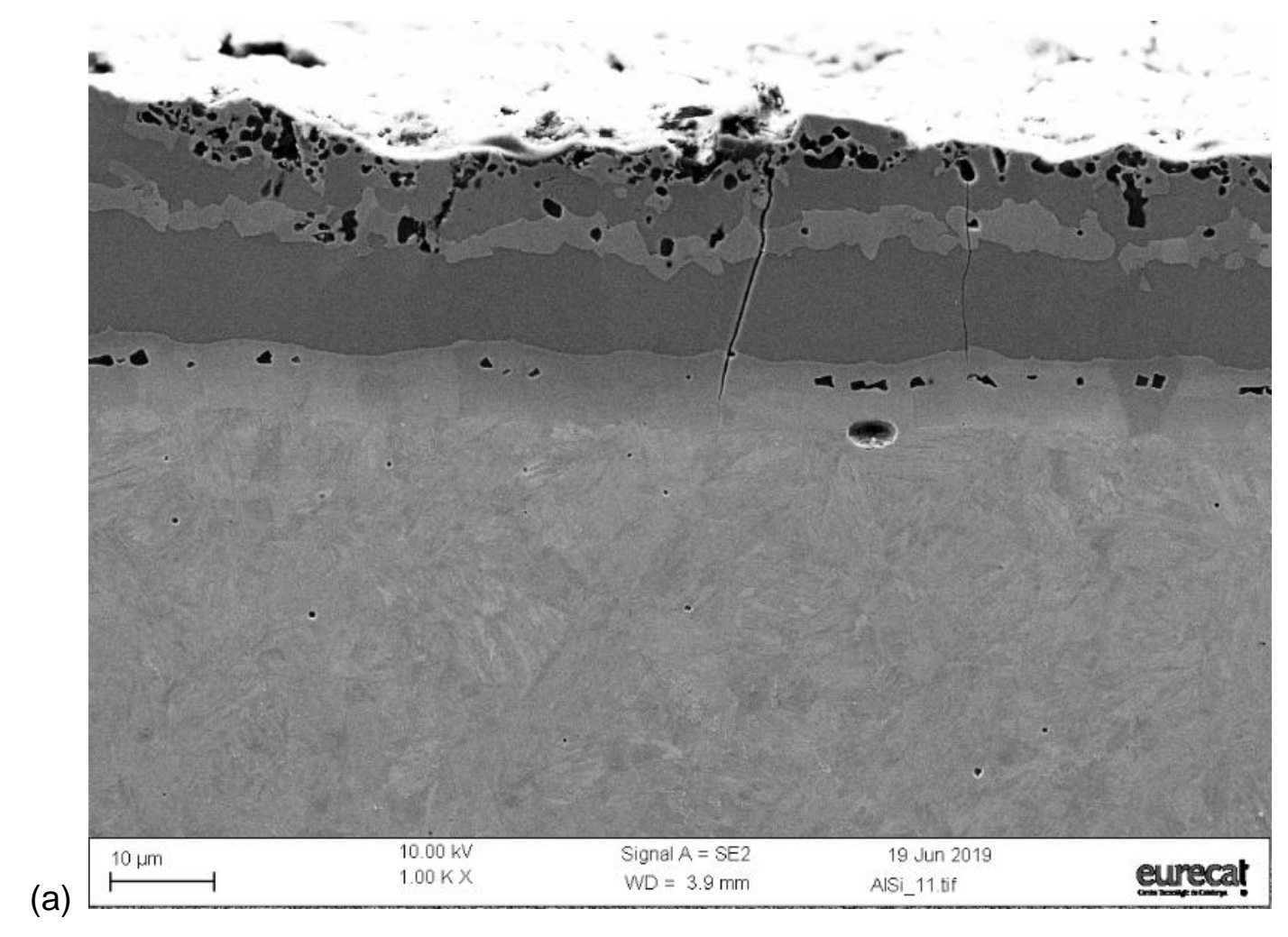




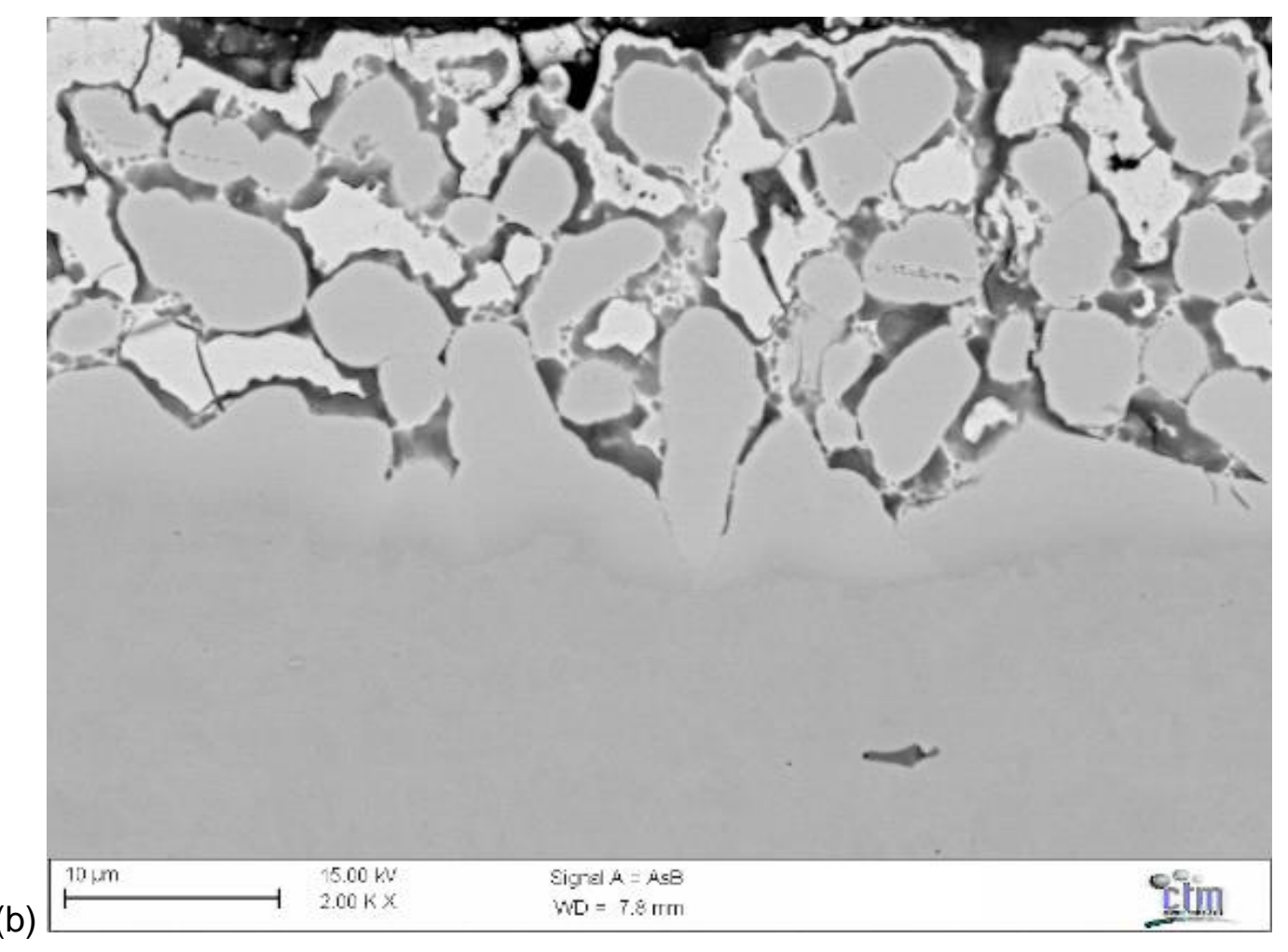




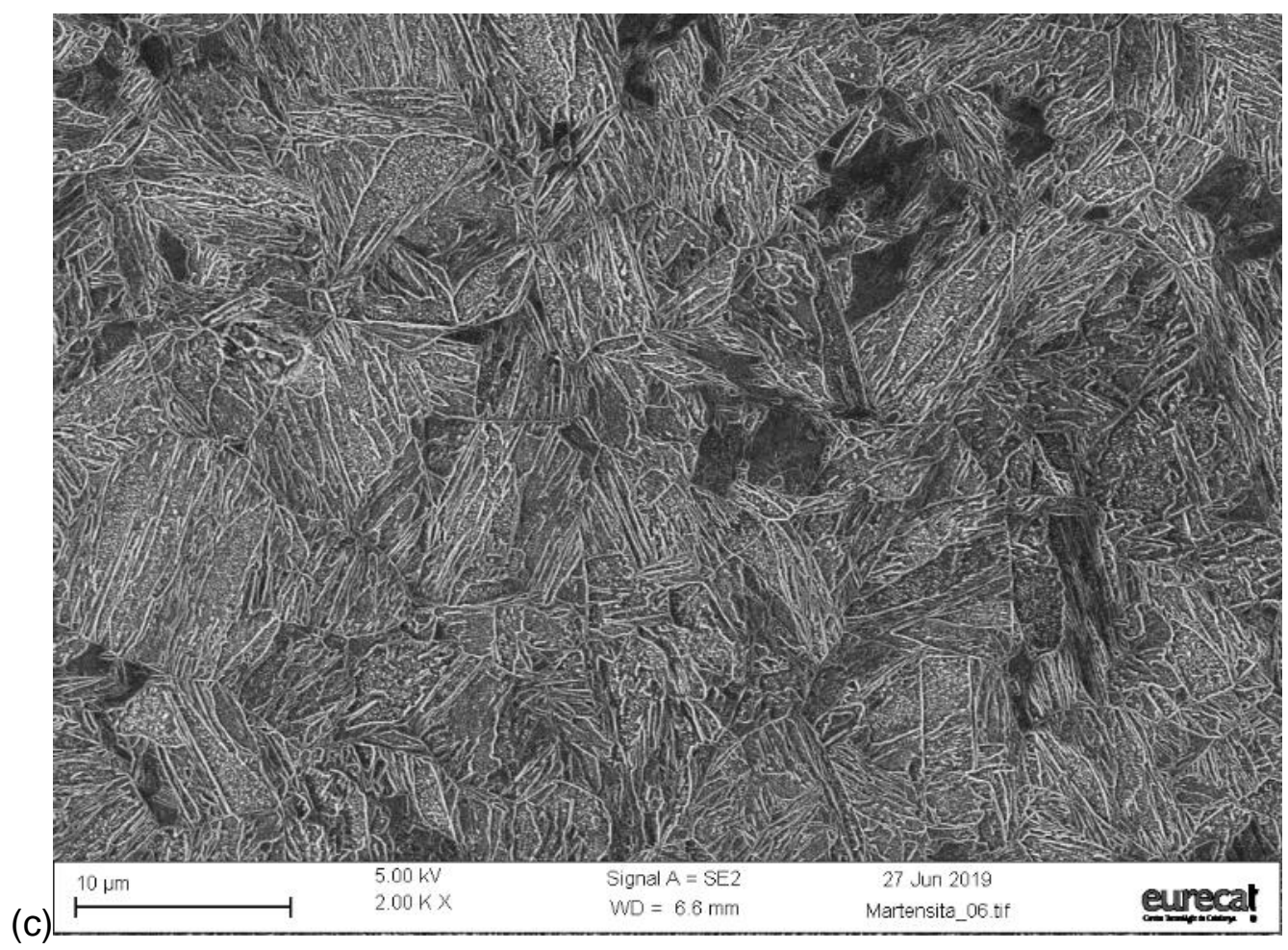

Figure 2: Descriptive cross-sectional SEM images of the coated samples. (a) AlSi coating; (b) GI90/90 coating: Zn-saturated Fe (dark) surrounded by $\Gamma$-Zn (bright). Details can be found in the body text. (c) Martensitic microstructure in a thin sheet. 


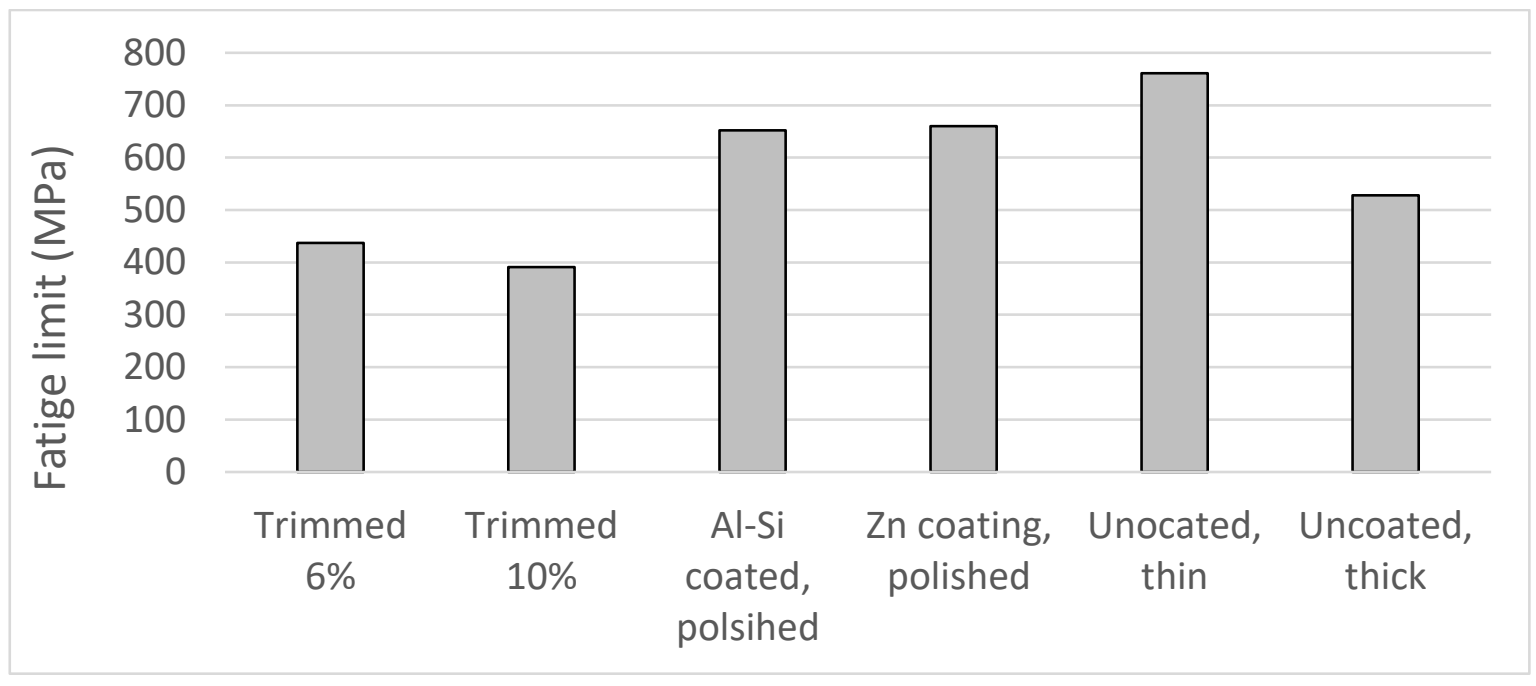

Figure 3: Fatigue limit of press hardened 22MnB5 steel.

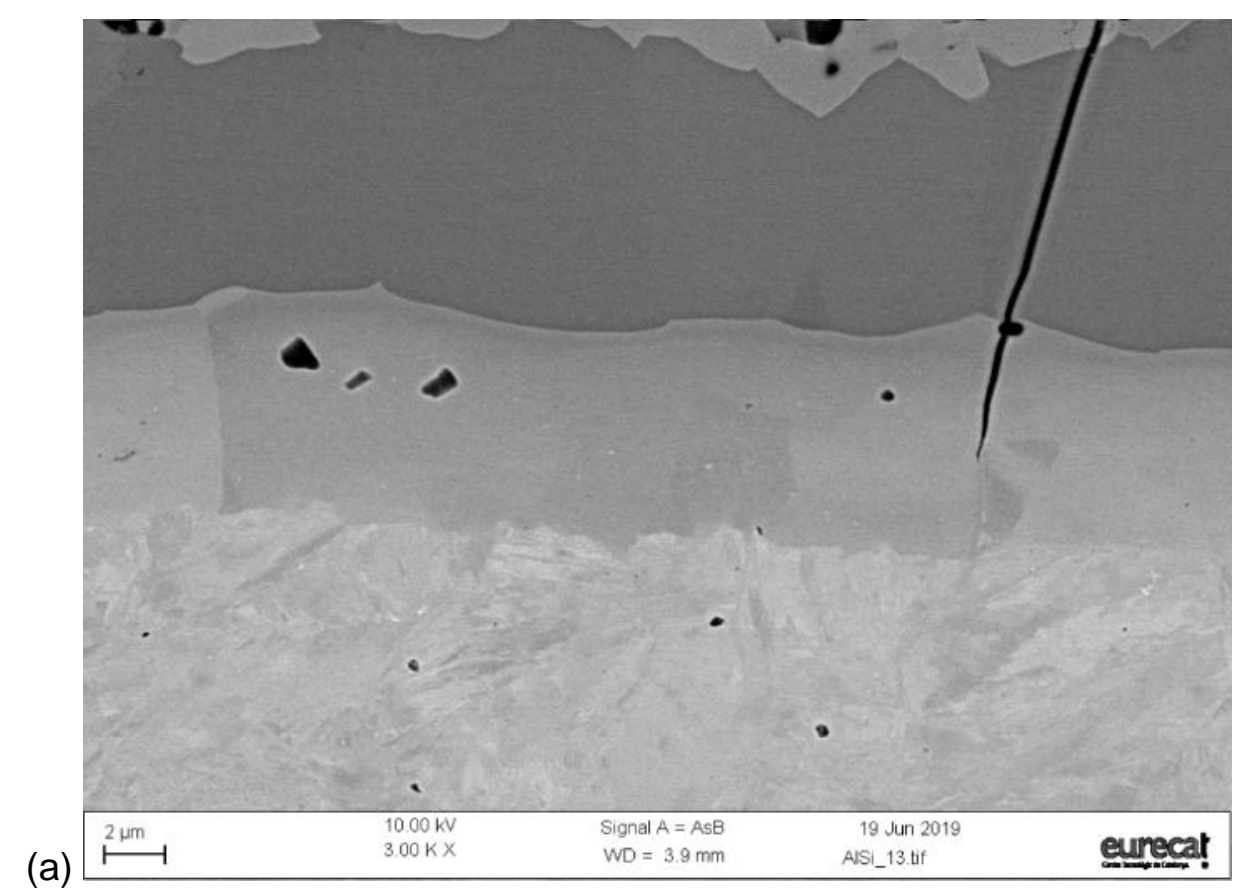


(b)

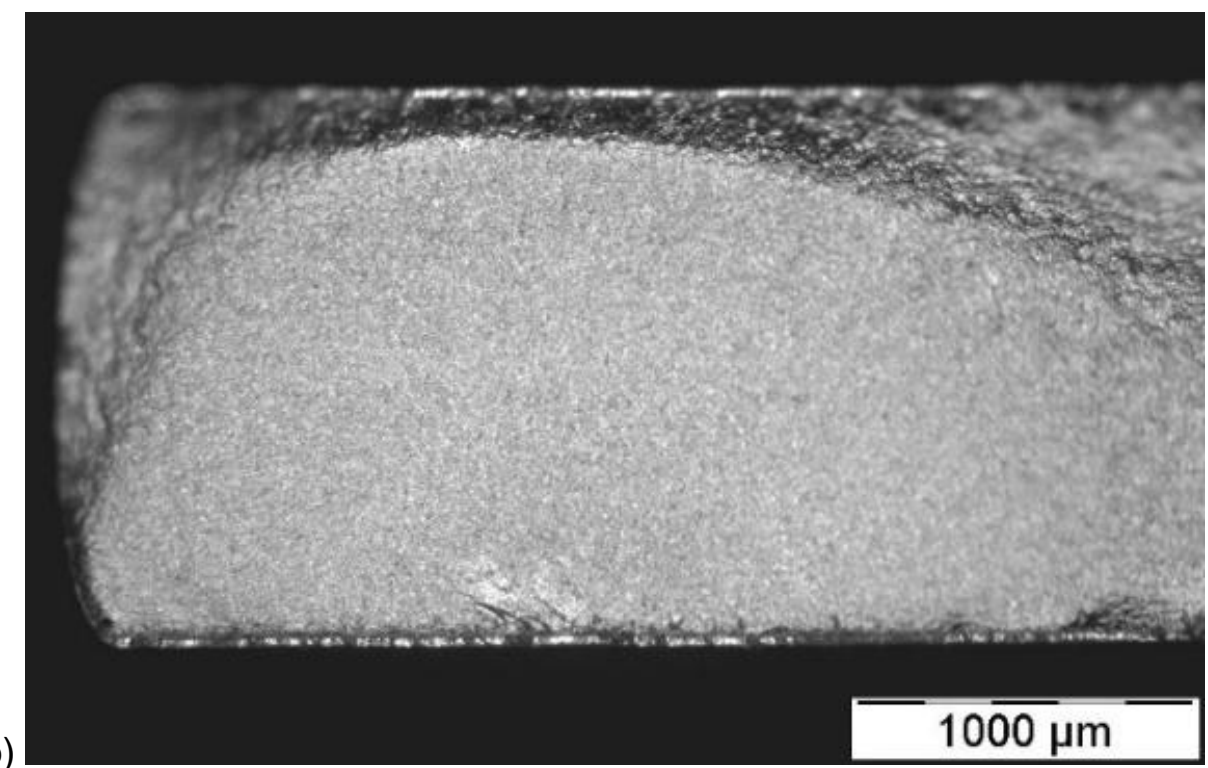




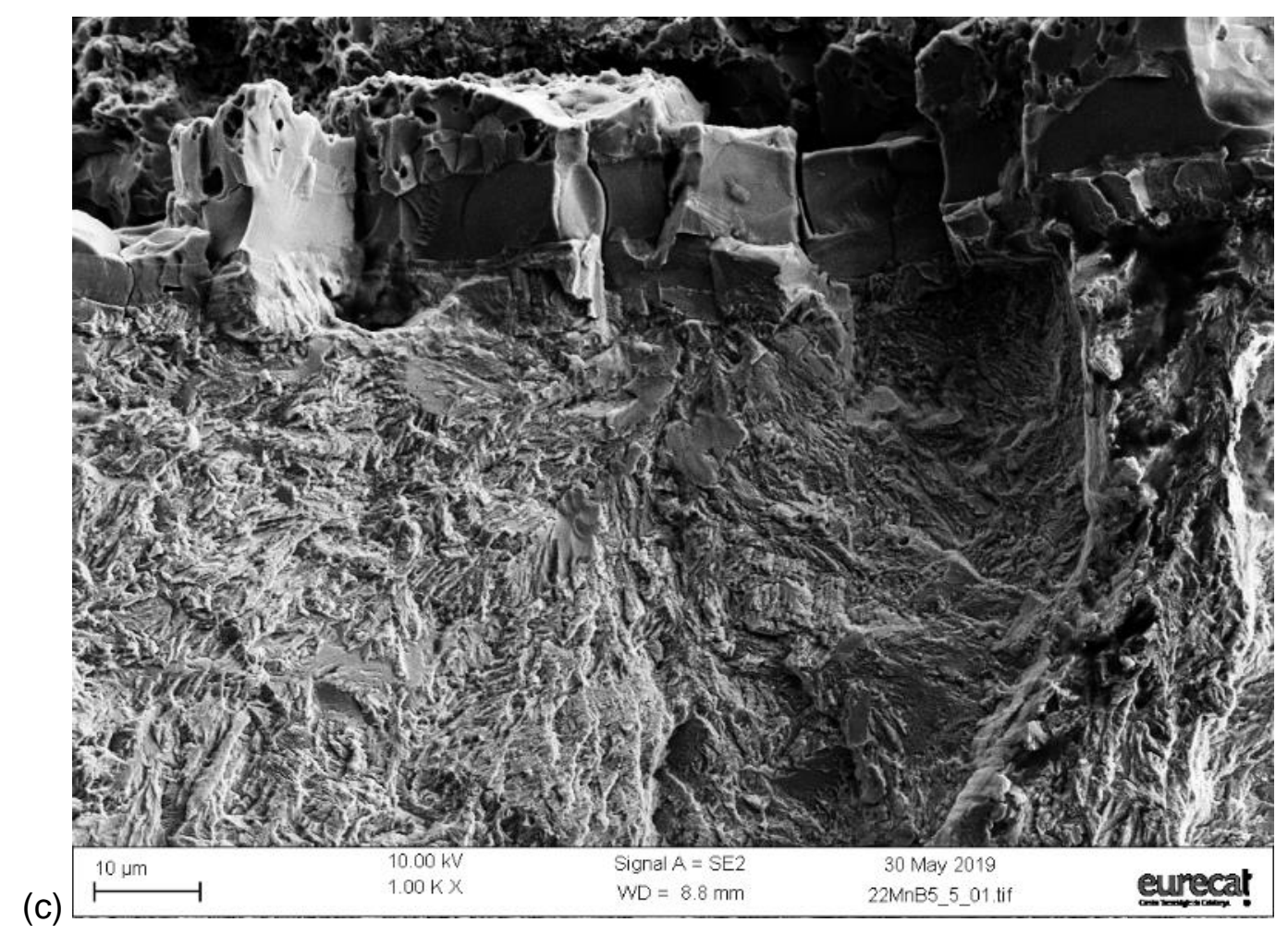




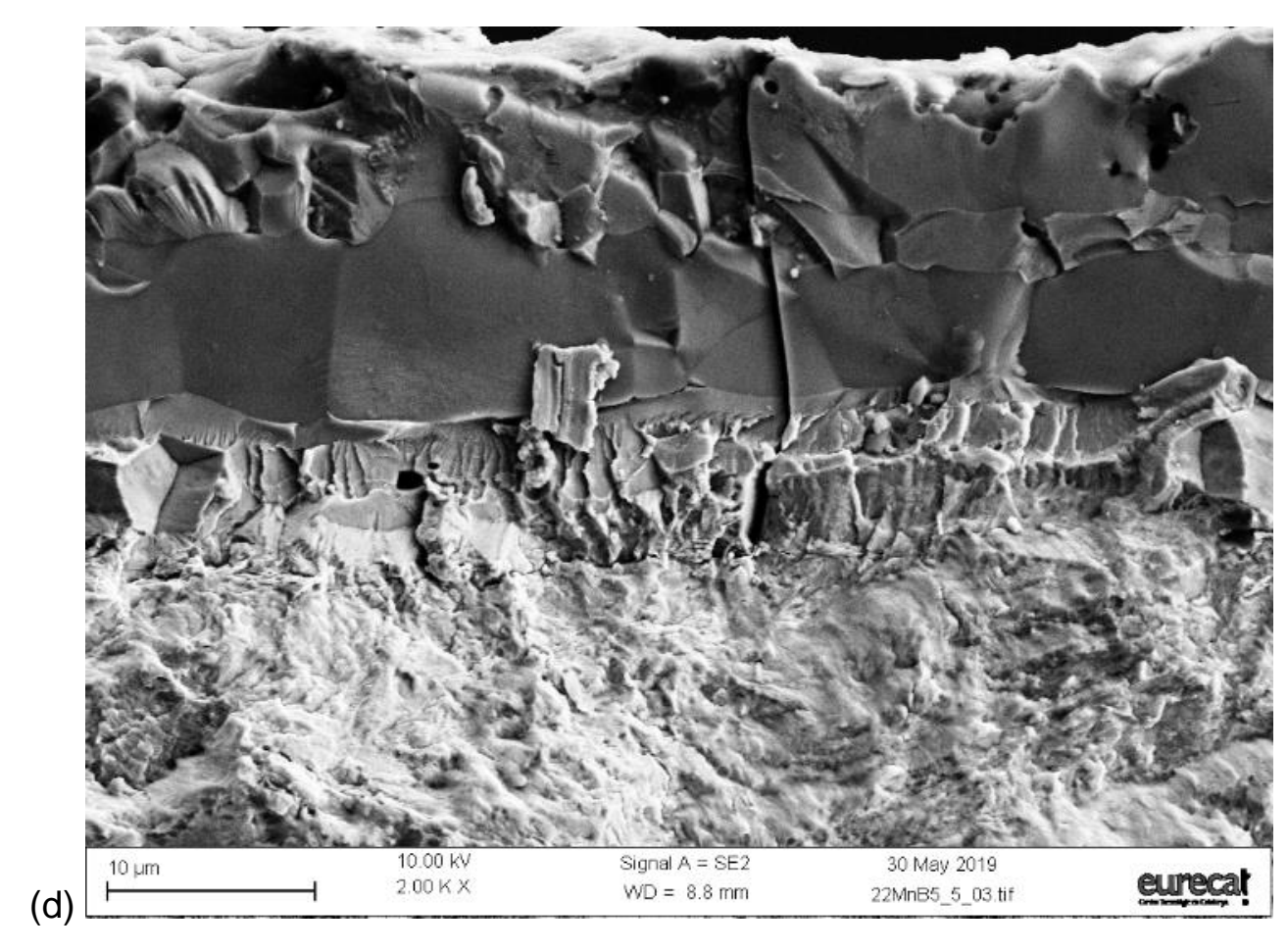




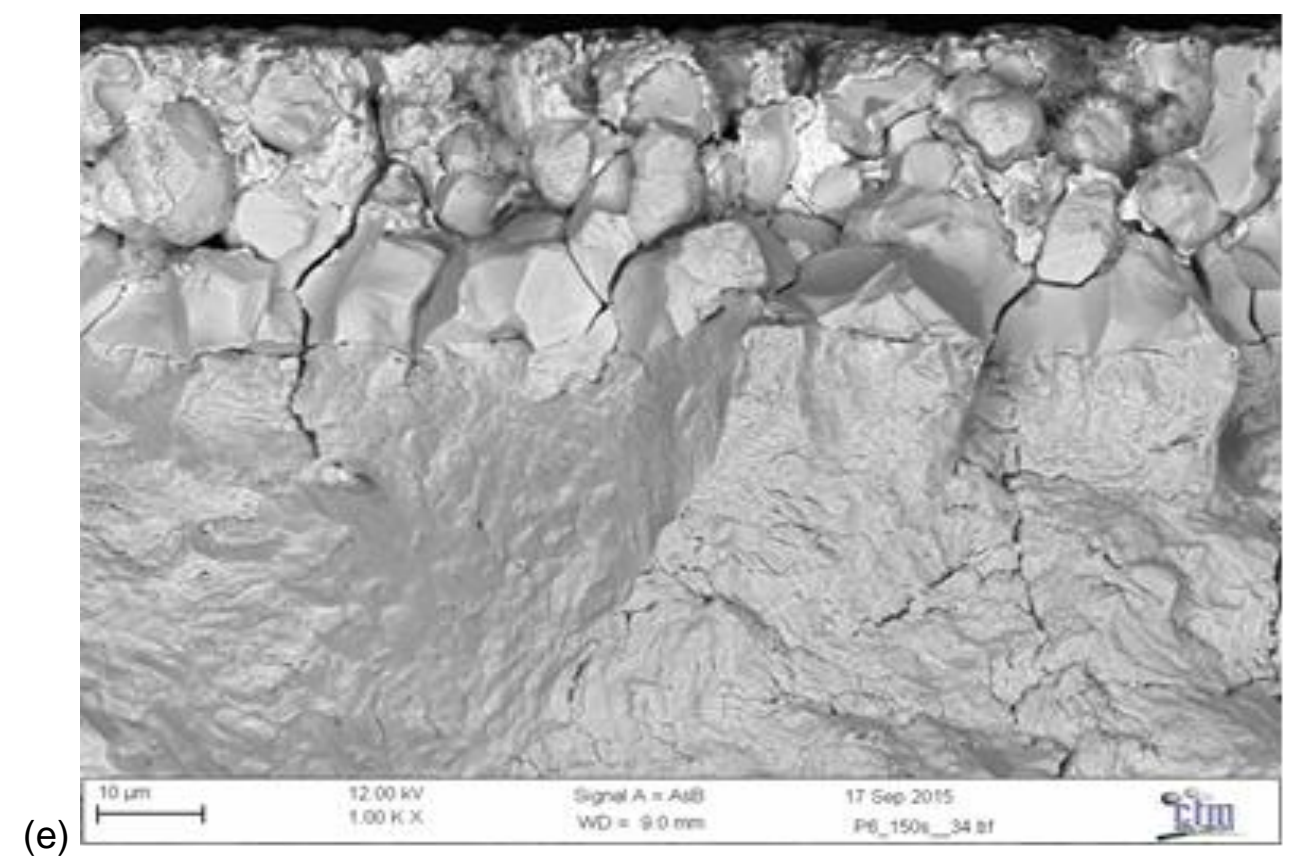

Figure 4: Fatigue origins associated to cracks in the coating, in coated specimens with polished edges. (a) Detail of figure 4(a) to show that the coating cracks stayed within the coating and do not grow into the substrate steel before fatigue testing. (b) Fatigued specimen with fatigue origin at the cracked coating. (c)-(d) Detail of the fatigue origin. (e) Fracture surface of fatigued Zn-coated specimen showing that cracks in the $\mathrm{Zn}$ coating are the fatigue origin and propagated into the steel substrate during fatigue tests. 


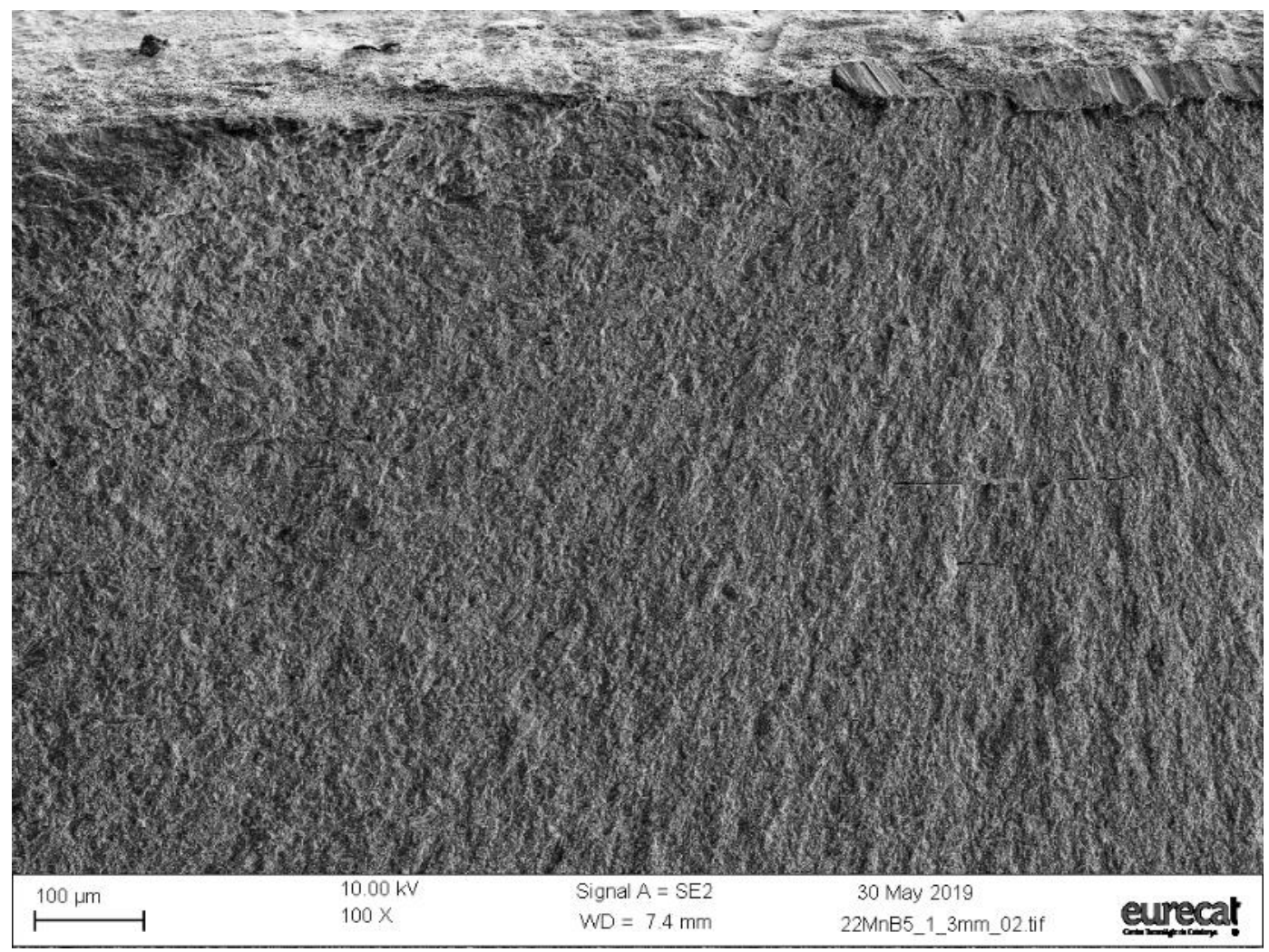

(a)

nal $\mathrm{A}=\mathrm{SE} 2$

30 May 201

encear 


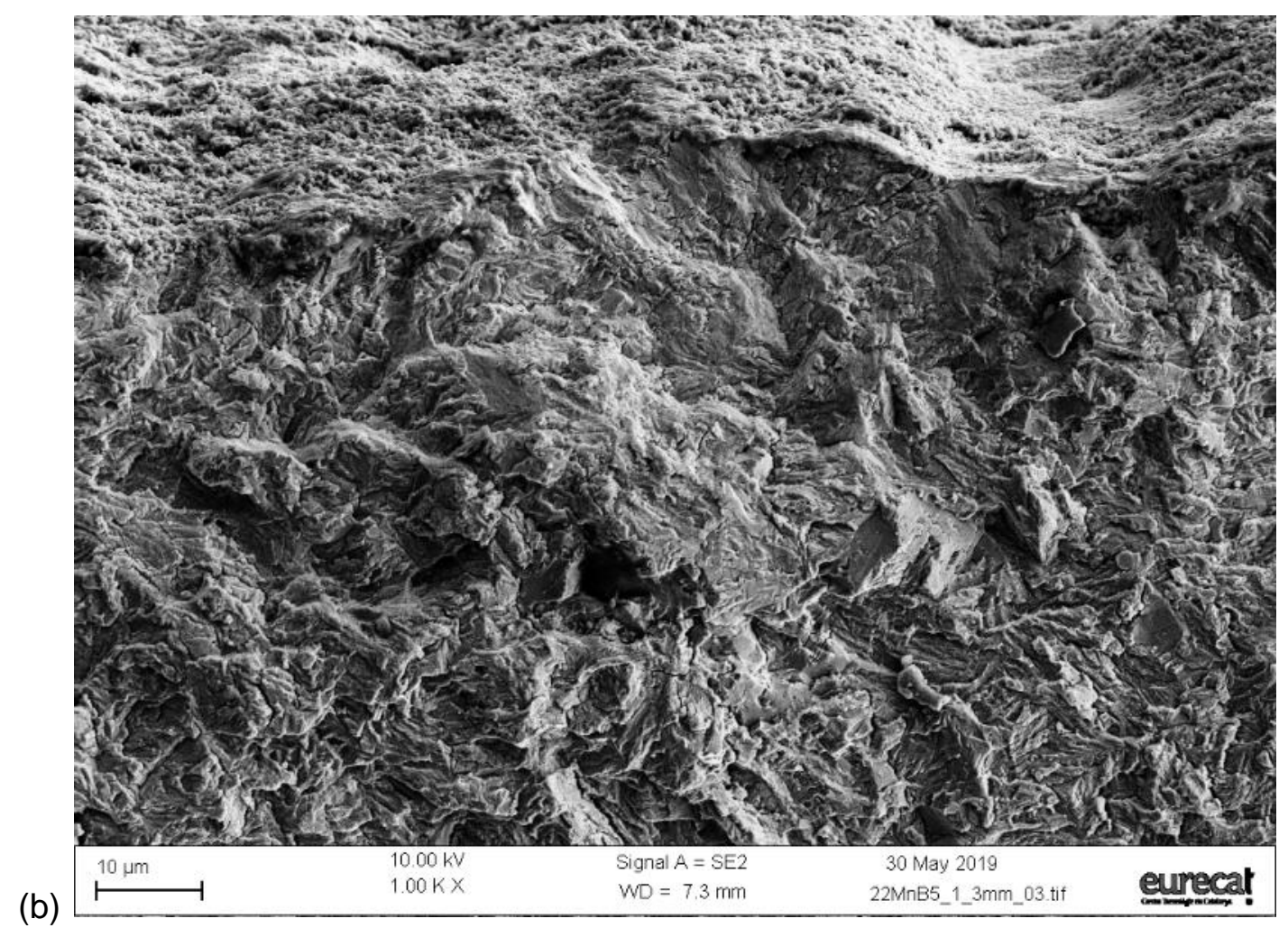

Figure 5: (a) Fatigue origins associated to surface irregularities in uncoated thick specimens. (b) Detail of the fatigue crack initiation site. 


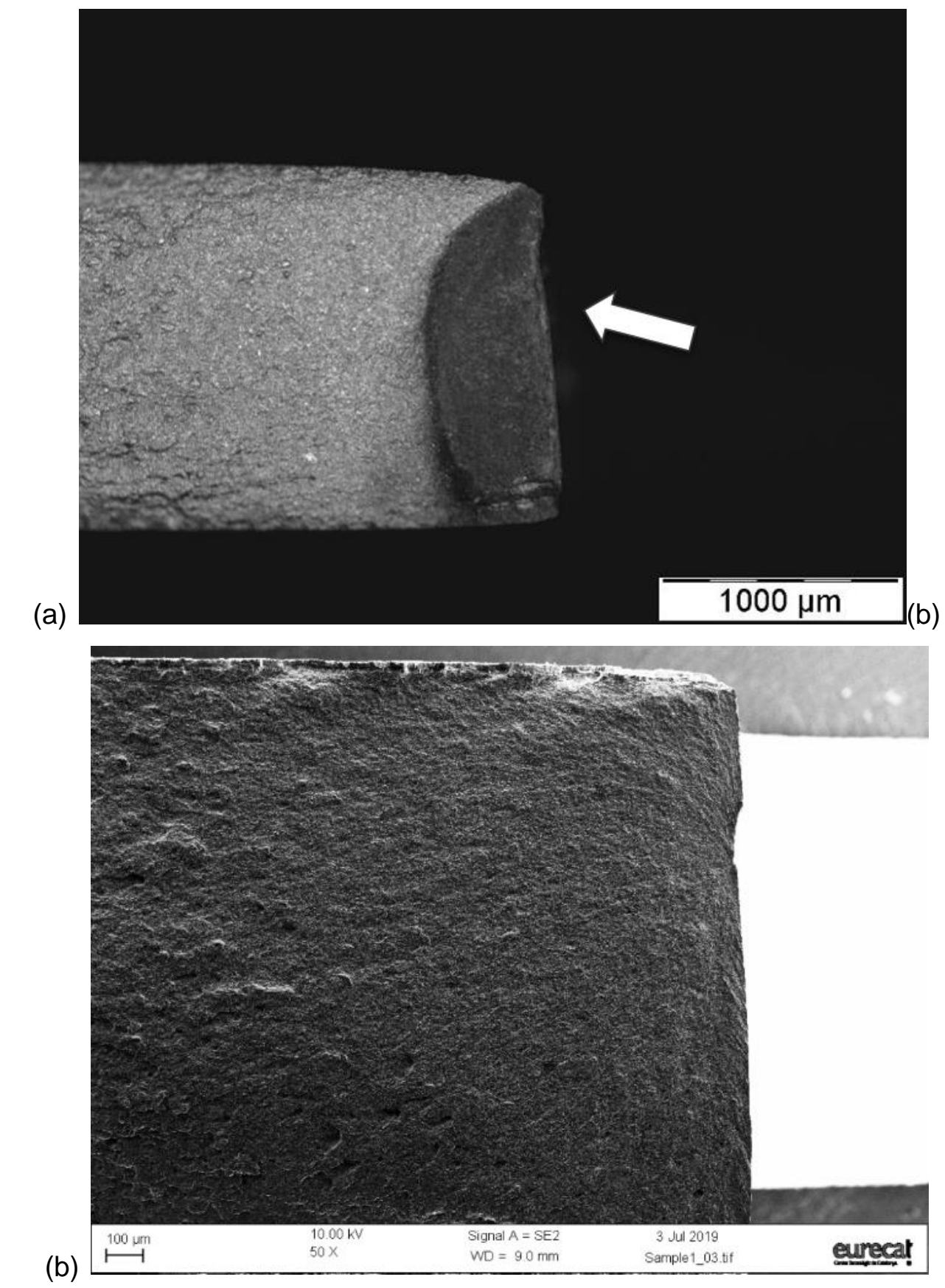




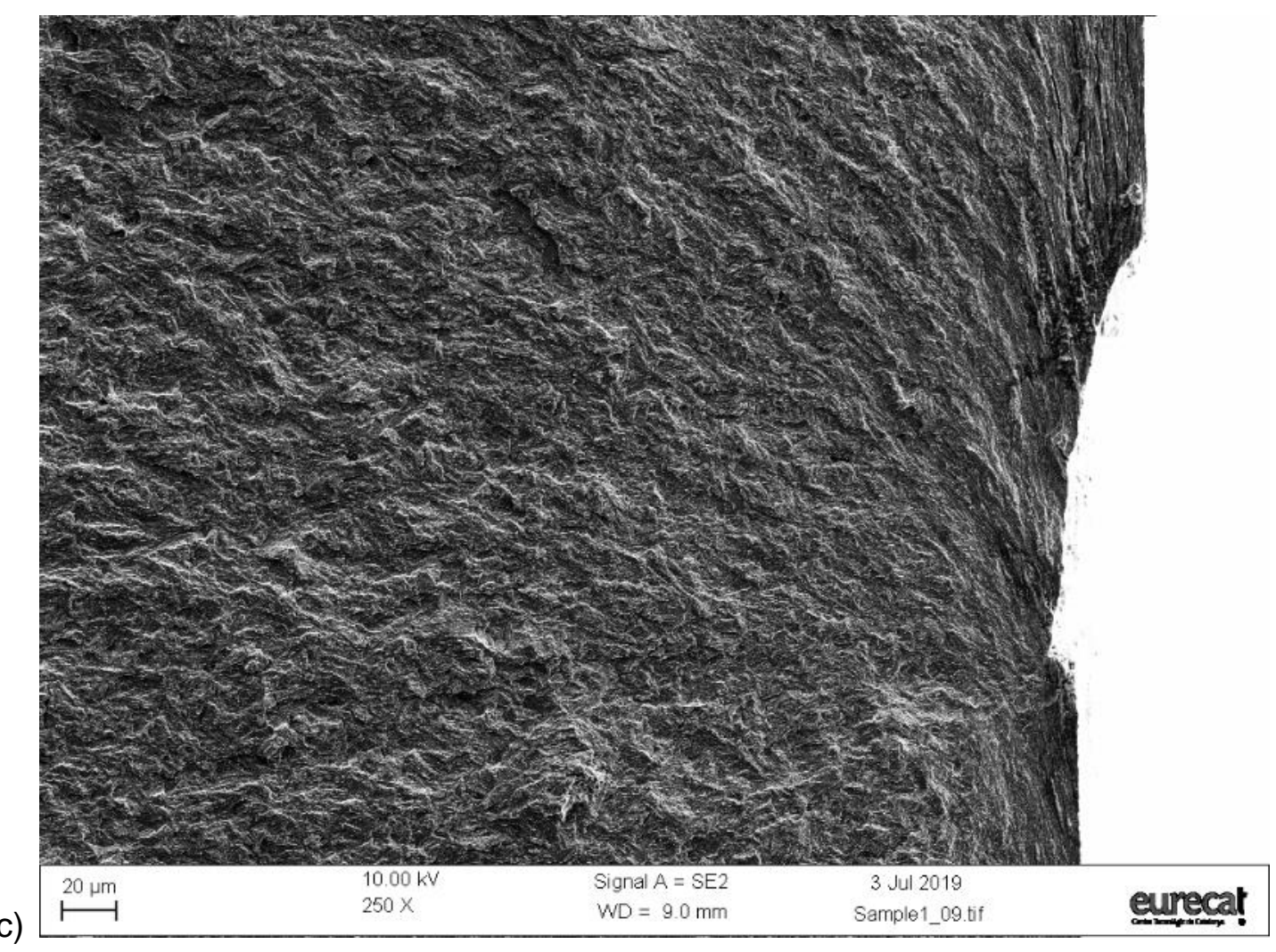

Figure 6: Fatigue origins associated to edge damage in trimmed $6 \%$ specimens. The arrow points the location of fatigue initiation. (a) Optical image of etched specimen to show the crack nucleation origin. (b)-(c) SEM images. 


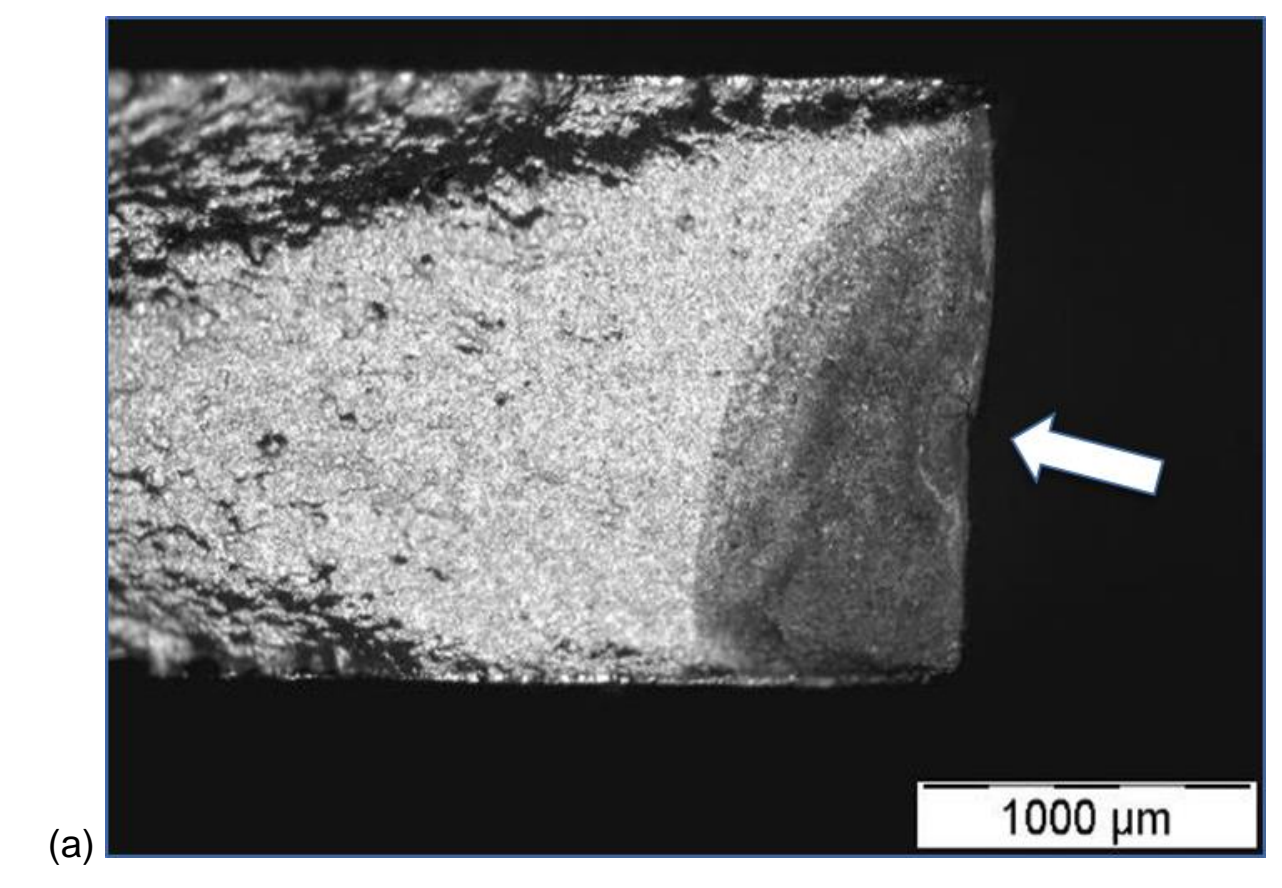




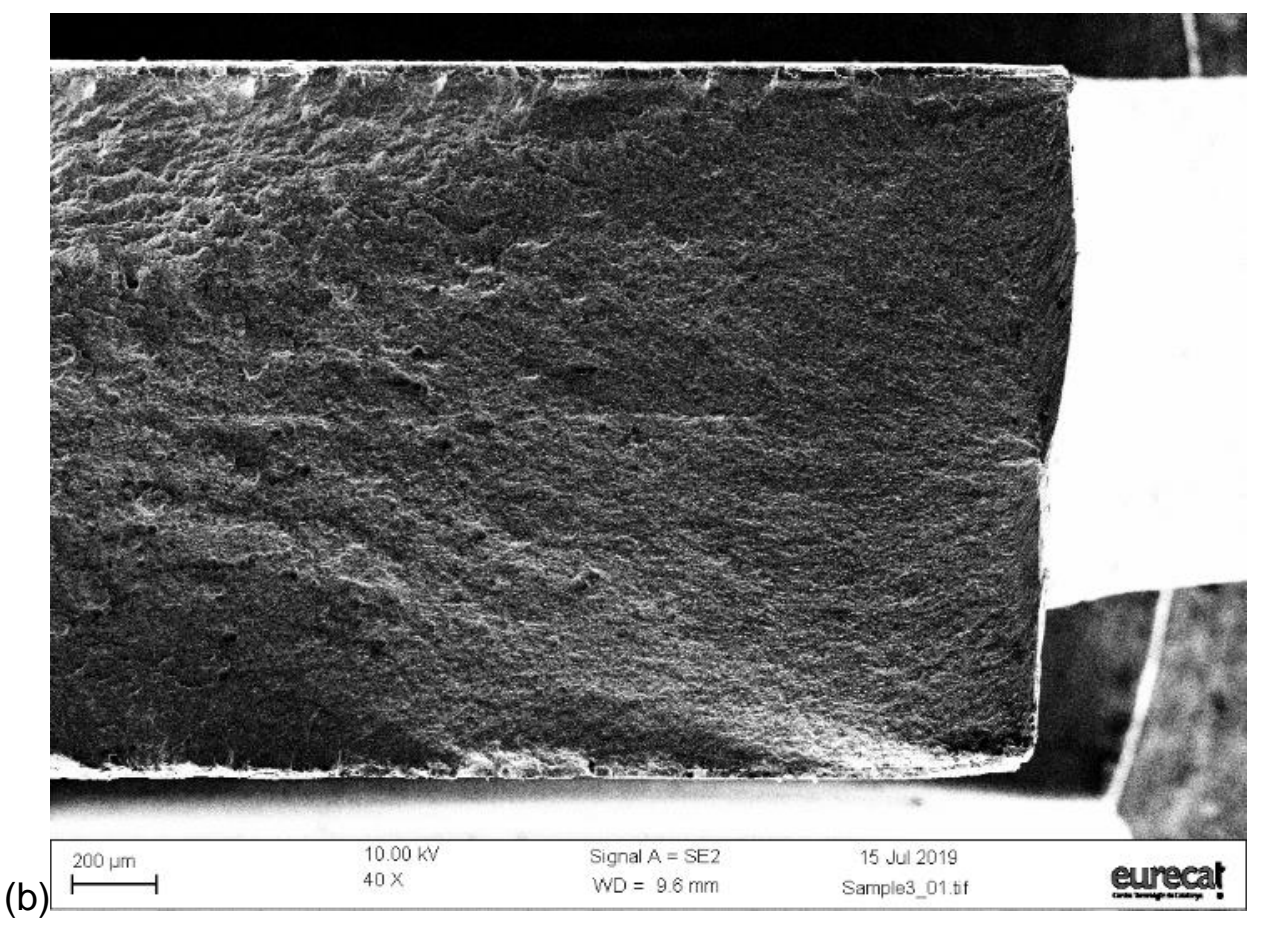




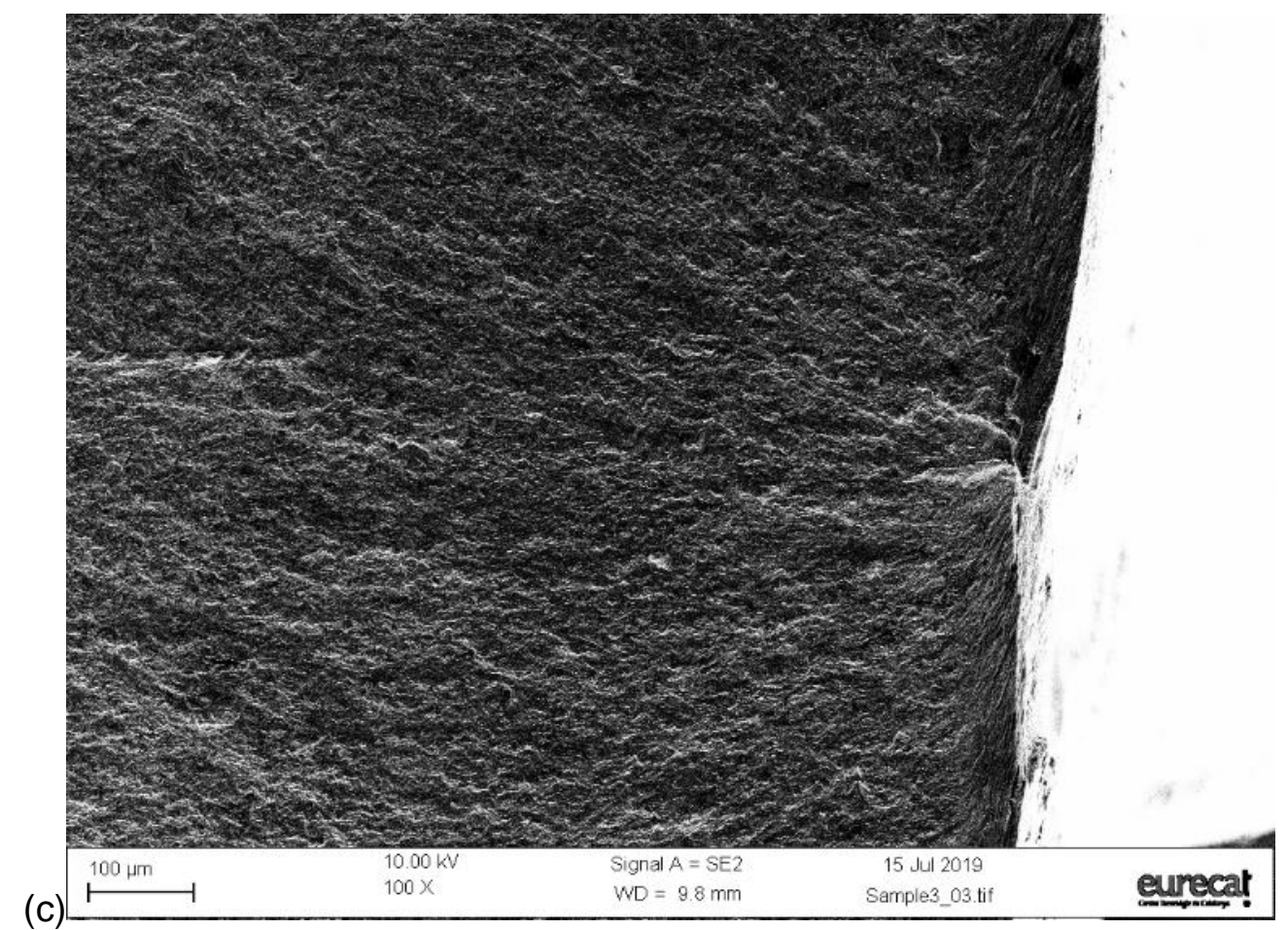

Figure 7: Fatigue origins associated to edge damage in trimmed $10 \%$ specimens. The arrow points the location of fatigue initiation. (a) Optical image of etched specimen to show the crack nucleation origin. (b)-(c) SEM images 


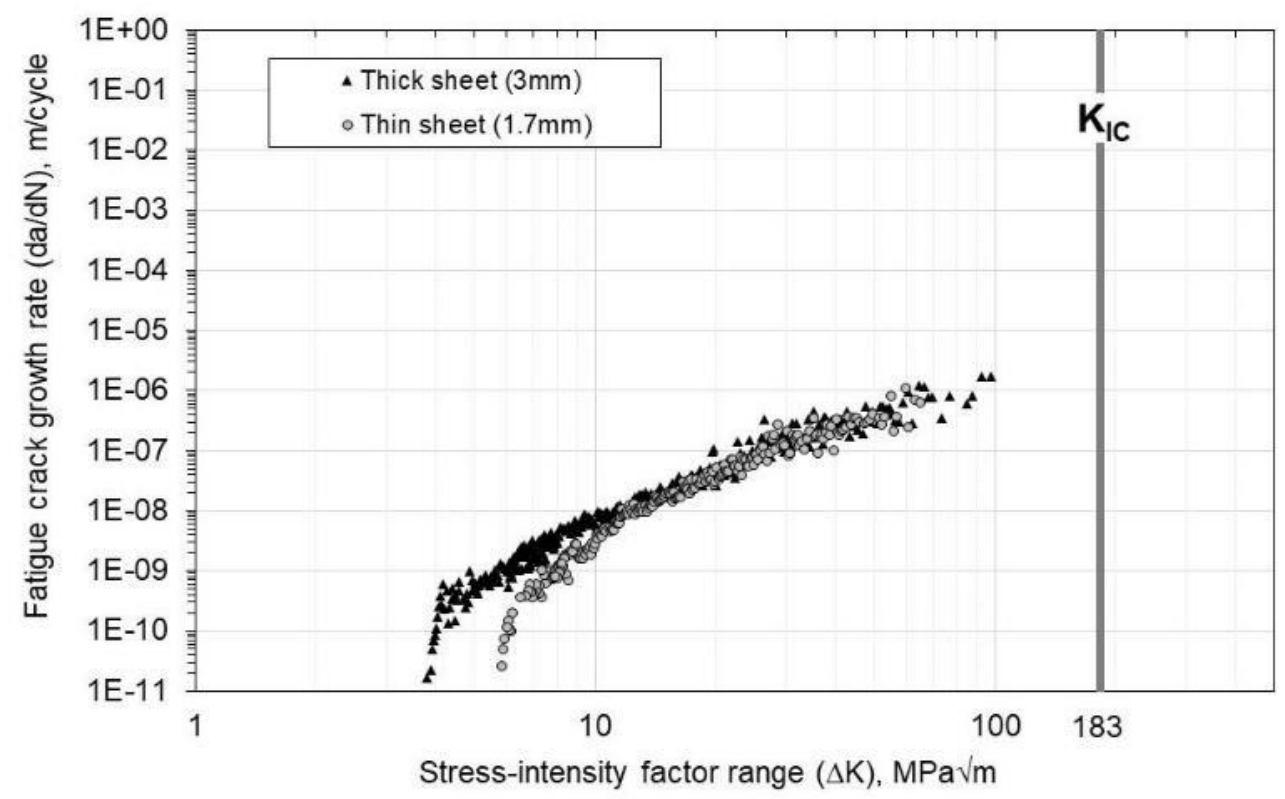

Figure 8: Fatigue crack growth rate of press hardened 22MnB5. Fracture toughness $\left(K_{/ c}\right)$ is also plotted. 
(a)
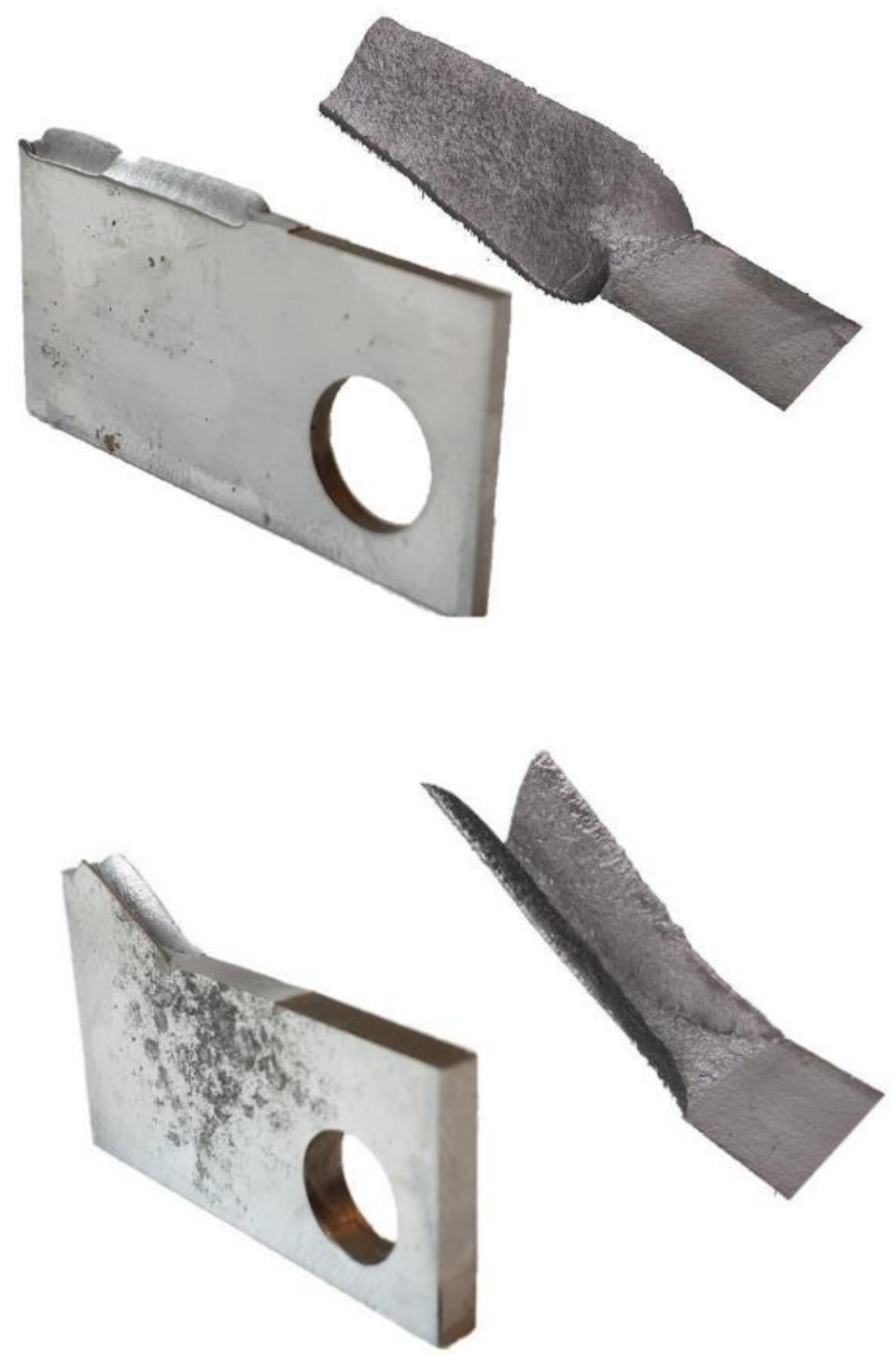

(b) 
Figure 9: Fracture aspect of CT the specimens used for fatigue crack growth evaluation (optical image with detailed view of the fracture area with optical profilometry). (a) The presence of shear lips in thick specimens $(3 \mathrm{~mm})$ indicates a mixedmode stress state. (b) The slant fracture feature in thin specimens $(1.7 \mathrm{~mm})$ is associated to a plane stress state.

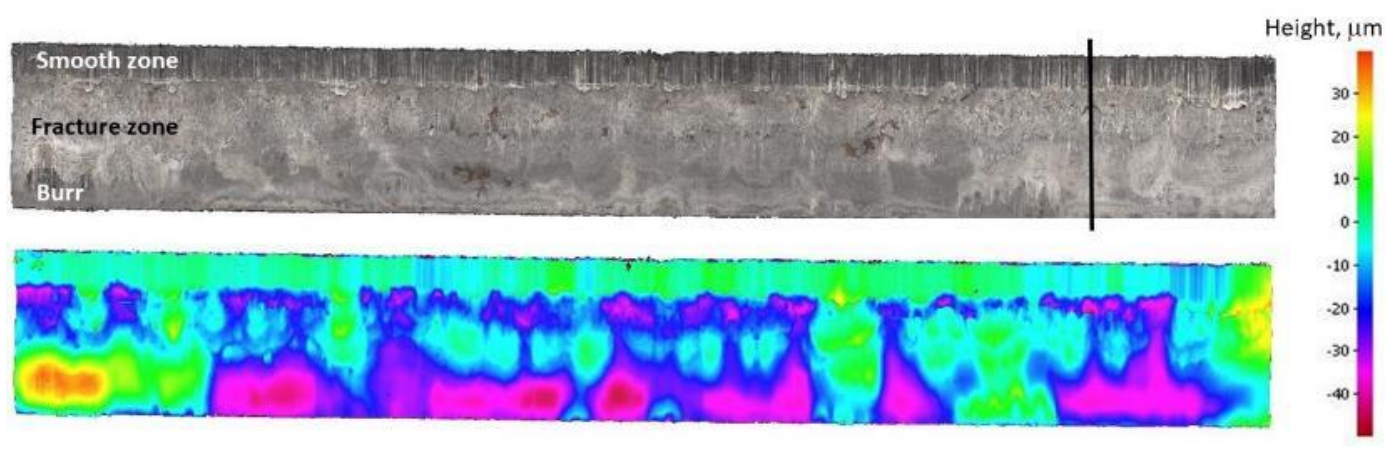

(a)

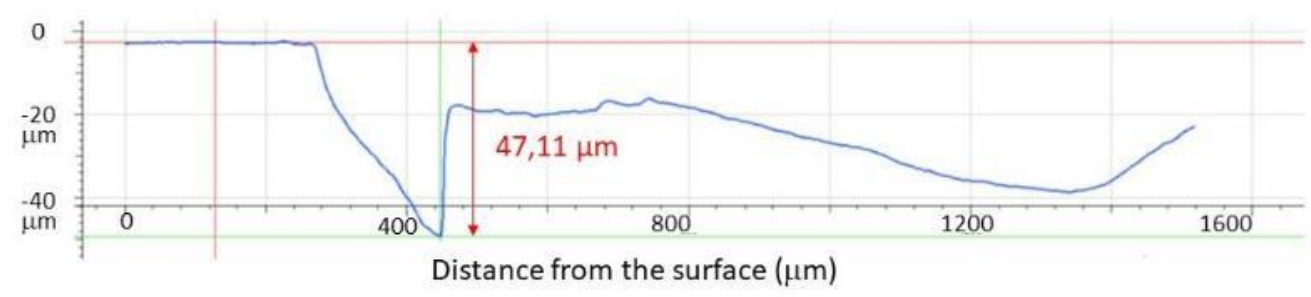

(b)

Figure 10: (a) Lateral view of a fatigue test specimen, showing the trimmed edge. The smooth zone is at the top and the fracture and burr zones is at the bottom. (b) Profile of the area with the deepest surface defect $(47 \mu \mathrm{m})$ for trimmed specimens ( $6 \%$ clearance), marked by a black line in figure (a). 


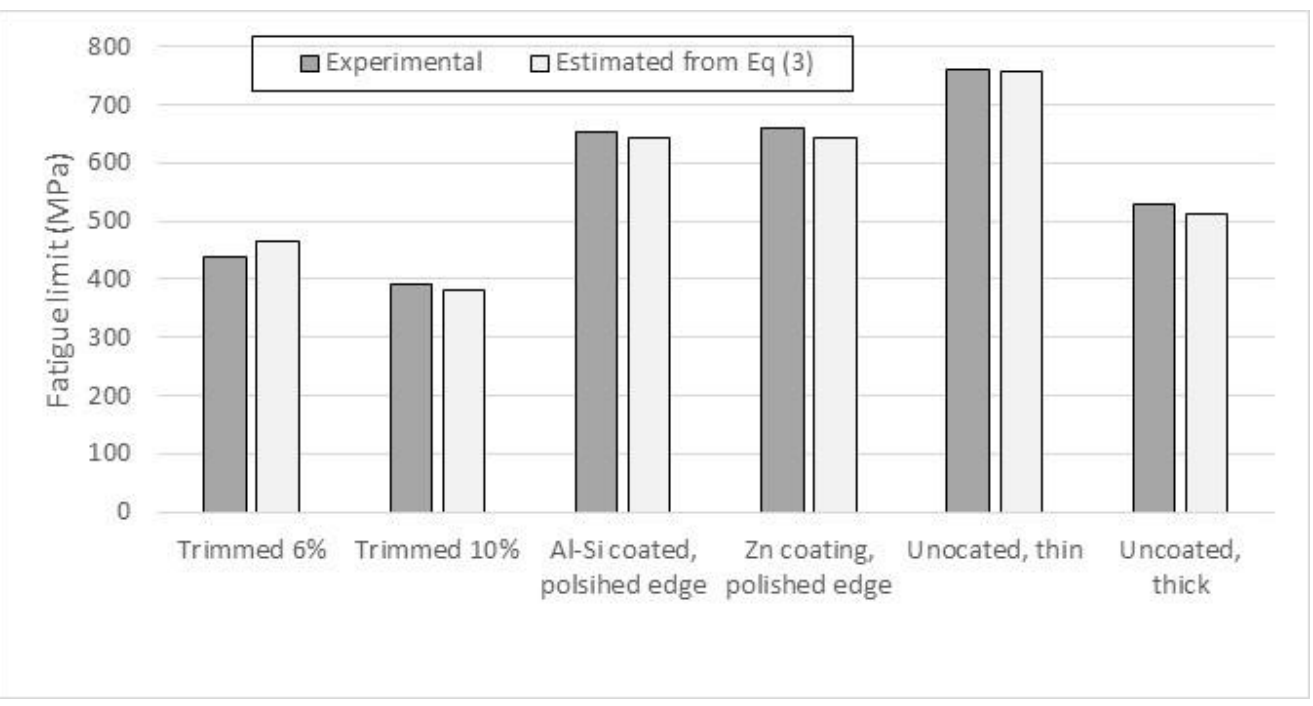

Figure 11: Comparison of experimental fatigue limit values (in terms of maximum stress) and estimated values from Eq (4) using as $\mathrm{a}_{0}$ the values reported in table 3. 


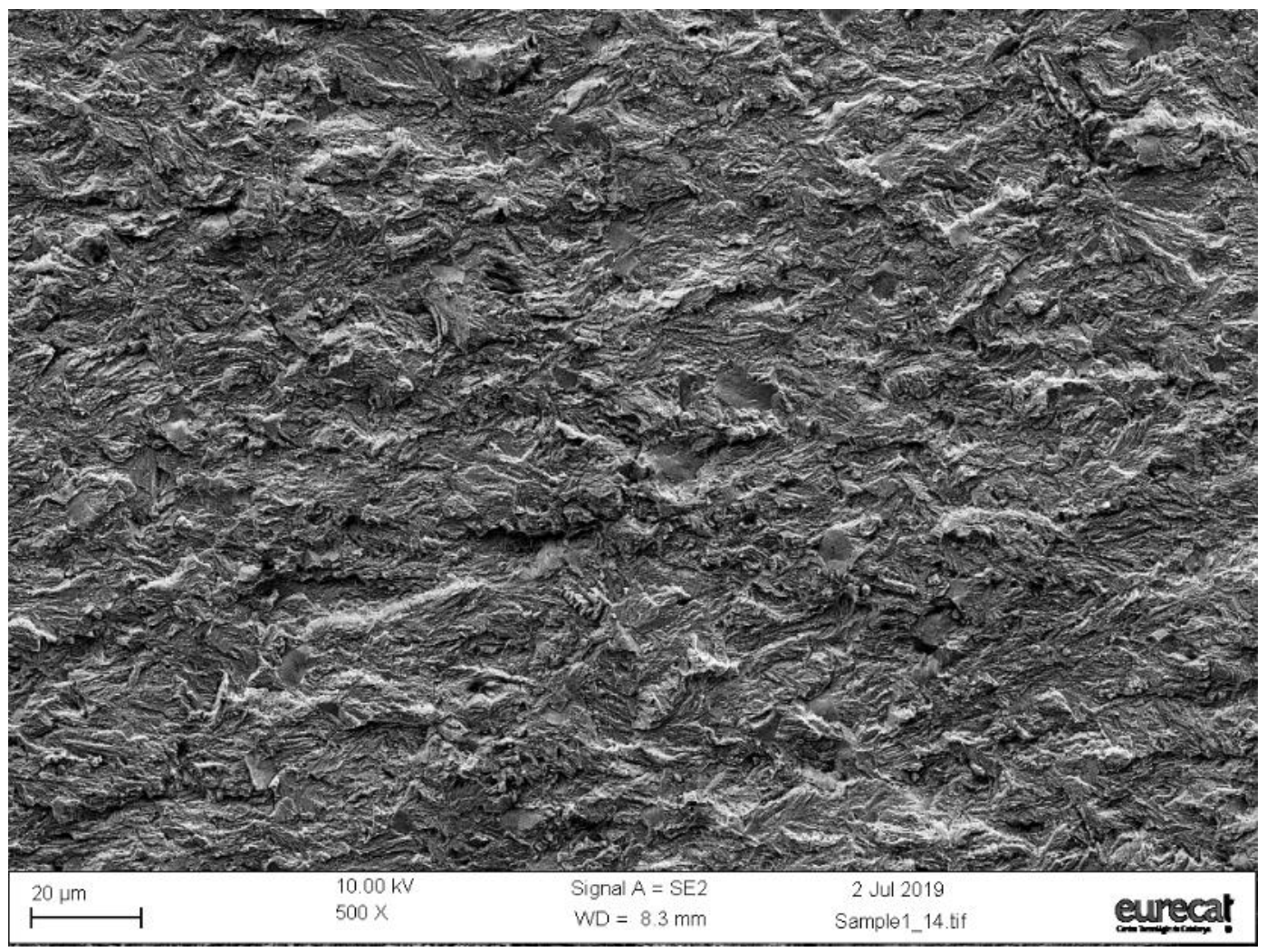

Figure 12: Fatigue fracture surface inspected by SEM in thin specimens for CT specimens, used for crack propagation rate tests. 